\title{
Evaluation of anti-tumor activity of ethanolic extract of Glycyrrhiza glabra against Ehrlich ascites carcinoma in swiss albino mice
}

\author{
Jayanthi M. K. ${ }^{1}$, SubbaRao V. Madhunapantula ${ }^{2}$, Divya K. Reddy ${ }^{1}$, \\ K. Mryuthunjaya ${ }^{3}$, Manjula S. N. ${ }^{1}$
}

${ }^{1}$ Department of Pharmacology, ${ }^{2}$ Department of Biochemistry, ${ }^{3}$ Department of Pharmacognosy, JSS Medical College, Mysuru, Karnataka, India

Received: 18 July 2016

Revised: 25 July 2016

Accepted: 23 August 2016

*Correspondence to:

Dr. Jayanthi M. K.,

Email: dr14jayagatti@

gmail.com,

Copyright: (C) the author(s), publisher and licensee Medip Academy. This is an openaccess article distributed under the terms of the Creative Commons Attribution NonCommercial License, which permits unrestricted noncommercial use, distribution, and reproduction in any medium, provided the original work is properly cited.

\begin{abstract}
Background: Cancer is one of the most life threatening diseases which is in need of newer drug development. The use of plant products with potent antioxidant and cytotoxic activity is upcoming Studies reveal that herbal product have increased efficacy as well as decreased side effects, with this in mind the present study was undertaken to assess the antitumor activity of extracts of Glycyrrhiza glabra (GG) against ehrlich ascites carcinoma in swiss albino mice.

Methods: The extracts of roots of GG was collected and acute toxicity study was done following which the antitumor effect of extracts of GG was assessed by change in the body weight, mean survival time (MST), and percentage increased life span (\% ILS). MST of each group containing six mice was monitored by recording the mortality daily for 6 weeks and \% ILS was calculated. The hematological parameters and biochemical assays were also measured.

Results: Extracts of GG showed a significant reduction in \% increase in tumor induced body weight of the mice. The \% increase in life span was also significant in the higher dose of GG $(500 \mathrm{mg} / \mathrm{kg})$. The combination of GG with standard drug cisplatin had better efficacy in terms of \% ILS, hematological and biochemical parameters. The results obtained were statistically significant.

Conclusions: The antitumor activity studies measuring the viability of cancer cells when exposed to the ethanolic extract of Glycyrrhiza glabra showed a potent cell-killing effect, indicating the presence of anti-cancer principles in the preparation.
\end{abstract}

Keywords: GG, Ehrlich ascites carcinoma, Hematological parameter, Antitumor activity

\section{INTRODUCTION}

Cancer is a group of diseases involving abnormal cell growth with the potential to invade or spread to other parts of the body. ${ }^{1}$ Inspite of all advances in medical sciences, cancer a disease as old as mankind is globally a major health problem. ${ }^{1}$ Recent reports according to cancer fact sheets 297 , WHO estimated that cancer is the leading cause of death worldwide accounting for 8.2 million deaths in 2012. The most common causes of cancer death are due to lung (1.59 million deaths), liver
(745 000 deaths), stomach (723 000 deaths), colorectal (694 000 deaths), breast (521 000 deaths) and gastroesophageal cancer's (400 000 deaths)

Cancer is one of the most life-threatening diseases and serious public health problems in both developed and developing countries. This increase in the global cancer burden will be mainly due to disproportionate rise of newly diagnosed cancer cases in the developing countries such as India. India, China and Russia are predicted to account for more than half $(53 \%)$ of the cancer cases and 
$60 \%$ of the cancer related deaths. For the last several decades, natural products have played a very important role as chemotherapeutic agents, either in their natural forms or in synthetically modified forms. ${ }^{2}$ For instance, many agents with plant origins (paclitaxel, vinblastine, vincristine, camptothecin, and others) have already been applied as anticancer therapies.

In the treatment of cancer many synthetic and chemotherapeutic agents have been developed, that show various side effects like alopecia, skin eruptions, reduced immunity, secondary carcinogenesis, etc. Hence, to overcome these flaws and to make the course of treatment more convenient herbal drugs have been developed as they are known for no severe side effects. Ancient Indian medicinal science was based on the natural products of plant origin. Presently, research on anticancer drug development is largely dependent on exploring potential phytochemicals.

Glycyrrhiza glabra habitats are Southwest and Central Asia as well as subtropical and temperate areas of the planet, including Europe. The root is known as licorice and has a sweet odor .The genus Glycyrrhiza (Leguminosae) has around 30 types of species such as G.glabra, G uralensis, G. inflata, G. aspera, and Persian and Turkish licorices, which are determined as G. glabra var. violace. ${ }^{3}$ Glycyrrhiza glabra L., Fabaceae, is a tall, erect perennial herb with branched stalks which grow to $1.5 \mathrm{~m}$. G. glabra is a native of South-East Europe and South-West Asia, which includes Iran. It is among the world's most ancient herbal remedies with a wide range of pharmacological activities including expectorant, antitussive, emollient, anti-inflammatory, antipyretic, antiviral, antibacterial, antiprotozoal, hepatoprotective, antitumor, vasorelaxant, antiplatelet aggregation, immunomodulatory, endocrinological, antidepressant, memory enhancing, sedative, muscle relaxant and antifungal effects. ${ }^{4}$ The most important bioactive components of Glycyrrhiza glabra root are triterpinoid saponin like glycyrrhizin, glycyrrhetinic acid (GA) and phenolics like liquiritin, liquiritigenin and glabridin5 . Most of the pharmacological activities shown by glycyrrhiza extract are attributed to its aglycone saponins, $18 \beta$-glycyrrhetinic acid. It has been reviewed and reported that most of the plants containing flavonoids and saponins possess anti-inflammatory and analgesic activity. $^{6}$

Glycyrrhetinic acid has a semi steroidal structure and its synthetic derivative, carbenoxolone has been used for peptic ulcer treatment. Glycyrrhetinic acid also shows various CNS activities like anticonvulsant activity in rat and mice, memory improvement activity in mice, antidepressant and cerebroprotective effect. Glycyrrhiza glabra, also known as licorice, is native to the Mediterranean and to certain areas of Asia. It is composed of triterpene saponins, flavonoids, polysaccharides, pectins, simple sugars, amino acids, mineral salts, and various other substances. ${ }^{7}$
As it well proven in many studies it has medicinally useful compounds like phenols which have good antioxidant property, there can be accessed for cytotoxicity, they could be a renewable source of bioactive anticancer material. Therefore, in this study the possible cytotoxic and toxic effects of the roots of G. glabra were assessed in mice.

\section{METHODS}

\section{Plant material}

Roots of Glycyrrhiza glabra were collected from Mysore district, Karnataka, India and was authenticated by Dr. M.N. Naganandini, Assistant Professor, Department of Pharmacognosy, JSSCP, Mysore. The roots of plant were cleaned to remove impurities and shade dried. The coarsely powdered leaves were weighed and stored in air tight containers. The coarsely powdered shade dried roots of the plant Glycyrrhiza glabra was extracted with ethanol by soxhlet extraction method for 25 hours. After completion of extraction the extract was filtered, concentrated using Rotavap and stored under airtight containers.

\section{Animals}

The experiments were carried out on 8-10 weeks old Swiss albino mice of either sex weighing $25 \pm 5 \mathrm{gm}$. Animals used in the study were procured from the Central animal house of JSS University, Mysuru. The animal care and handling was carried out in accordance to guidelines issued by the Institutional Animal Ethics Committee, JSS Medical College, Mysore, and Karnataka. Animals were acclimatized to the experimental room for one week prior to the experiment. Animals were maintained under controlled conditions of temperature $(23 \pm 30 \mathrm{C})$ and humidity $(50 \pm 5 \%)$ and were caged in sterile polypropylene cages containing sterile paddy husk as bedding material with maximum of four animals in each cage. The mice were fed on standard food pellets and water ad libitum. The studies conducted were approved by the Institutional Ethical Committee, JSS Medical College, Mysore, and Karnataka.

\section{Chemicals}

The chemicals were obtained from the indicated commercial sources. Extracts of GG, phosphate buffered saline (PBS). Cisplatin .All the reagents used were of analytical reagent grade.

\section{Cell lines}

EAC (Ehrlich Ascites Carcinoma) cells, obtained from JSS College of Pharmacy, Mysore, Karnataka, India. The cell lines were maintained and propagated intraperitonially by serial transplantation in adult Swiss albino mice. 


\section{Standard drug (Cisplatin)}

The standard drug Cisplatin Vials were obtained from Threveni Pharma, Mysore.

\section{Preparation of test samples}

The test compound was prepared by using distilled water. Cisplatin at a dose of $3.5 \mathrm{mg} / \mathrm{kg}$ was used as reference standard. The suspensions of test and standard were prepared freshly. The test compounds were administered orally and standard drug administered intraperitoneally (i.p).

\section{Acute toxicity study ${ }^{8}$}

Acute toxicity study of the extract of Glycyrrhiza glabra was performed using swiss albino mice according to OECD guidelines no. 425. The extract was found safe up to $2000 \mathrm{mg} / \mathrm{kg}$ in swiss albino mice.

\section{Study design}

The experimental design was planned for evaluating In vivo anticancer activity of ethanolic extract of GG against EAC cell lines induced liquid tumor model after wide range of searching many research articles. ${ }^{9}$ The dose 250 and $500 \mathrm{mg} / \mathrm{kg}$ were chosen for this study is based on MTD obtained from acute toxicity study. The animals are divided into 5 groups $(\mathrm{n}=12)$

\section{Induction of liquid tumor}

The procured EAC cells were maintained in vivo Swiss albino mice i.p. The ascetic fluid is aspirated from the peritoneal cavity of EAC bearing mice, after 15 days of tumor transplantation. These withdrawn cells after calculating total no. of viable cells, are used to induce ascitic tumor at concentration $2 \times 106$ EAC cells $(0.25 \mathrm{ml}$ of stock suspension), and injected intraperitoneally to each mice. ${ }^{10}$

\section{Treatment schedule for assessment of in vivo antitumor potential}

After 24 hours, EAC transplanted, all the groups were treated respectively. This was marked as day " 0 ". GroupI were being injected with distilled water p.o, group-II was served as standard Cisplatin $(3.5 \mathrm{mg} / \mathrm{kg})$ i.p, groupIII was served as GG $250 \mathrm{mg} / \mathrm{kg}$ p.o, group -IV GG 500 $\mathrm{mg} / \mathrm{kg}$, p.o and group-V $1.75 \mathrm{mg} / \mathrm{kg}+\mathrm{GG} 500 \mathrm{mg} / \mathrm{kg}$ once daily for 9 consecutive days. After administrations of last dose 6 mice from each group were kept fasting for 18 hours and blood was collected by direct cardiac puncture for the estimation of hematological determination. Rest of animals in each groups were kept alive with food and water ad libitum to check the percentage increase in life span of the tumor host and also to determine the mean survival time (MST). Antitumor activity of GG extract was assessed by observation of changes with respect to the following parameters. ${ }^{10}$

- \% Increase in body weight as compared to day
"0"weight

Upon weighing the animals on the day of inoculation and once in 3 days in the post inoculation period the $\%$ increase in body weight was calculated as follows:

$\%$ increase in $\mathrm{wt}=($ animal $\mathrm{wt}$ on respective day/animal wt on day 0$)-1$ x 100

- Mean survival time (MST) and Increase in life span (\%ILS)

Total number of days an animal survived from the day of tumor inoculation was counted. Subsequently the mean survival time was calculated. The \%ILS was calculated as follows:

MST $=($ Day of first death + day of last death $) / 2$

ILS $(\%)=[($ Mean survival time of treated group / mean survival time of control group) - 1] X100

\section{- Hematological studies}

Hemoglobin level, RBC, WBC counts were measured from freely flowing tail vein blood. Differential leukocyte count of WBC was carried out from Leishman stained blood smears of normal, EAC control, and GG- treated groups, respectively. ${ }^{11}$

\section{- Biochemical assays}

SGPT, SGOT87, ALP, Blood Urea88, Serum Creatinine,

\section{Statistical analyses}

The experimental results were expressed as the mean \pm S.E.M. Data were assessed by ANOVA followed by post hoc Tukey's multiple comparison tests. P value of $` 0.05$ was considered as statistically significant.

\section{RESULTS}

There was a substantial increase in body weight was observed in EAC inoculated control mice with a maximum gain of $(67.19 \pm 6.178 \%)$ on day 15 compared to day 0 . The development of tumor was observed on day 6 th and continued till end of study. The Standard Cisplatin $(3.5 \mathrm{mg} / \mathrm{kg})$ treatment significantly reduced body weight $(-29.02 \pm 2.22 \%)$ compared to control. GG at a dose of $250 \mathrm{mg} / \mathrm{kg}$ treatment significantly reduced the tumor induced \% increase in the body weight $(46.47 \pm 3.64)$ and $\mathrm{GG}$ at a dose of $500 \mathrm{mg} / \mathrm{kg}$ with $(20.32 \pm 2.67 \%)$ when compared to control. The combination (Cisplatin $1.75 \mathrm{mg} / \mathrm{kg}+\mathrm{GG} 500 \mathrm{mg} / \mathrm{kg}$ ) 
reduced significantly tumor induced $\%$ increase in the body weight $(5.26 \pm 1.93)$ when compared to control and efficacy was comparable to standard. On $12^{\text {th }}, 15^{\text {th }}$ day all treated groups including the standard Cisplatin group significantly inhibited the percentage rise in body weight as compared to control. According to Figure 1 the test group showed significant decrease in body weight to control and efficacy was comparable with the standard.

Tables 1: The efficacy of combination treated in enhancing lifespan of tumor bearing animal was comparable to that of standard (cisplatin $3.5 \mathrm{mg} / \mathrm{kg}$ ) which was $158 \%$.

\begin{tabular}{|ll|l|}
\hline Treatment & MST & \% ILS \\
\hline Control & $21.17 \pm 0.749$ & - \\
\hline Cisplatin $(3.5 \mathrm{mg} / \mathrm{kg})$ & $54.50 \pm 5.9372^{\mathrm{a}}$ & $158 \%$ \\
\hline GG 250 mg/kg & $29.83 \pm 1.47^{\mathrm{b}}$ & $40.9 \%$ \\
\hline GG 500mg/kg & $35.66 \pm 1.229^{\mathrm{a}}$ & $68.44 \%$ \\
\hline $\begin{array}{l}\text { Cisplatin }(1.75 \mathrm{mg} / \mathrm{kg} \\
+ \text { GG 500 } \mathrm{mg} / \mathrm{kg})\end{array}$ & $41 \pm 1.639^{\mathrm{ab}}$ & $93.67 \%$ \\
\hline
\end{tabular}

Mean survival time of EAC inoculated mice was $21.17 \pm 0.749$ days. Standard cisplatin treatment at 3.5 $\mathrm{mg} / \mathrm{kg}$ also significantly enhanced the mean survival time to $54.50 \pm 5.937$ days when compared to control. The GG extract of $250 \mathrm{mg} / \mathrm{kg}$ and $500 \mathrm{mg} / \mathrm{kg}$ significantly increase the MST to $29.83 \pm 1.47,35.66 \pm 1.22$ respectively when compared to control. The combination (cisplatin 1.75 $\mathrm{mg} / \mathrm{kg}+\mathrm{GG} 500 \mathrm{mg}$ ) and significantly increased the MST to $41 \pm 1.69$ and efficacy was comparable to standard. The percent increase in lifespan (\% ILS) of animal treated with GG $250 \mathrm{mg} / \mathrm{kg}$ and $500 \mathrm{mg} / \mathrm{kg}$ was 40.9 , 68.44, the percentage increase in lifespan of combination (cisplatin $1.75 \mathrm{mg} / \mathrm{kg}+\mathrm{GG} 500 \mathrm{mg}$ ) treated was $93.67 \%$. The efficacy of combination treated in enhancing lifespan of tumor bearing animal was comparable to that of standard (cisplatin $3.5 \mathrm{mg} / \mathrm{kg}$ ) which was $158 \%$ as shown in Table1.

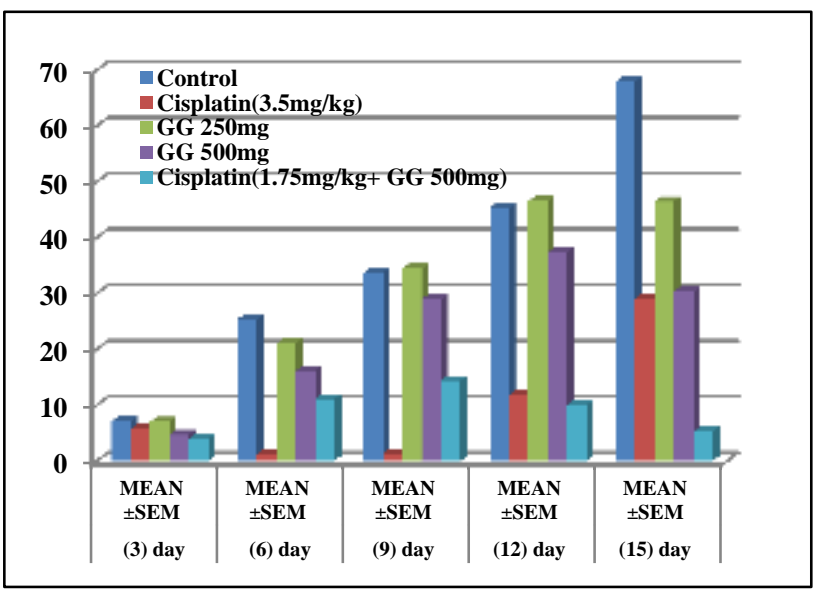

Figure 1: Significant decrease in body weight to control and efficacy was comparable with the standard.

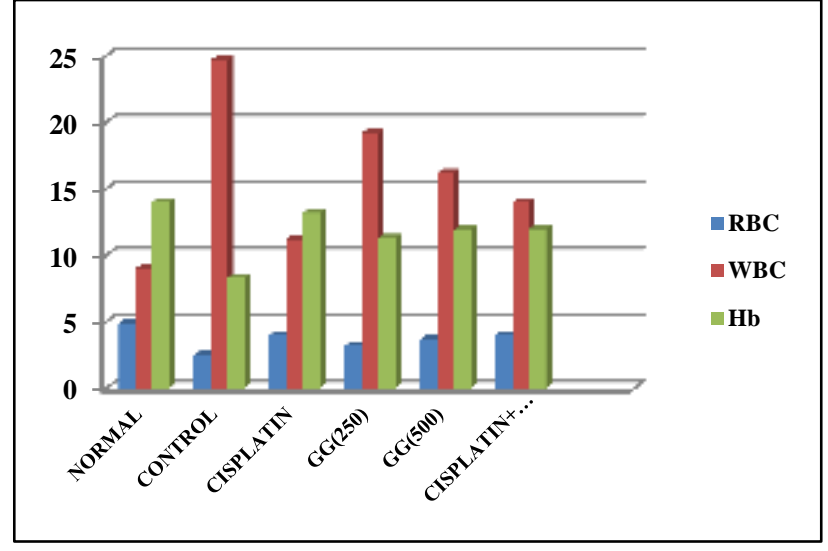

Figure 2: Effect of haematological parameters.

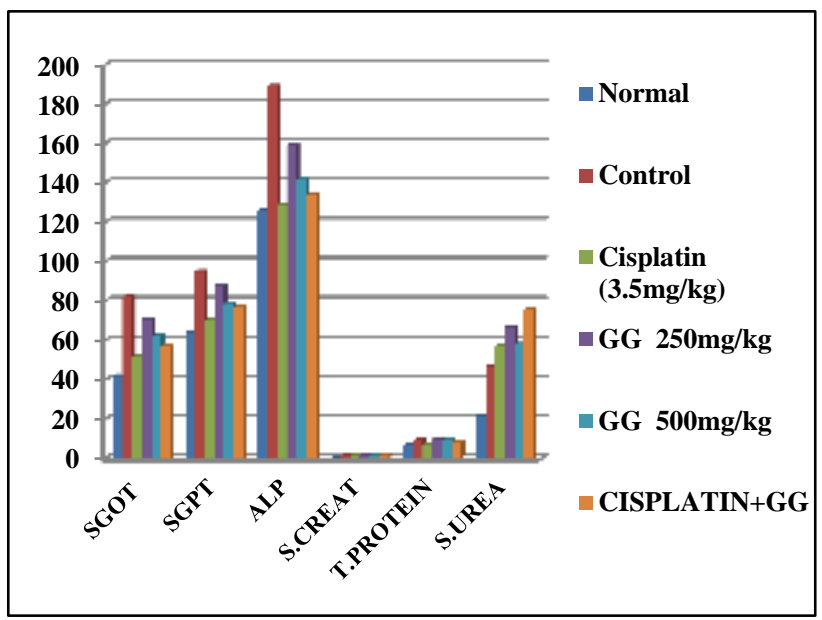

Figure 3: Effect on biochemical parameters.

The effect on serum creatinine is significantly reduced as compared to cisplatin, which usually causes increase in serum creatinine concentration as compared to control and levels of serum urea and total protein is increased compared to ciplastin as shown in Figure 2 and 3.

\section{DISCUSSION}

Recent upsurge in identifying natural products of dietary origin associated with high degree of safety margins has been found to be beneficial as potent cancer chemo preventive agents. Comprehensive reviews provide strong evidence that high intake of vegetables and fruits are associated with reduced cancer incidence.

The finding of the present study reveals that administration of the alcoholic extract of Glycyrrhiza glabra, Lam at both dose levels $(250 \mathrm{mg} / \mathrm{kg}$ body weight and $500 \mathrm{mg} / \mathrm{kg}$ body weight) has showed potent antioxidant and anticancer activity in EAC induced tumour models.

The toxicity of drug before starting the in-vivo evaluation was checked by acute toxicity test, where the MTD was 
seen more than $2000 \mathrm{mg} /$ per $\mathrm{kg}$ body weight in Swiss albino rats.

In the Ascites tumor model, a significant increase in body weight of the animals was observed in EAC bearing control mice owing to the rapid and progressive accumulation of Ascites tumor cells. Treatment with ethanolic extract of GG caused at both doses and the combination group showed marked reduction in the increase in body weight of tumor bearing mice when compared to control group in a dose dependent manner. Also ethanolic extract $250 \mathrm{mg} / \mathrm{kg}$ and $500 \mathrm{mg} / \mathrm{kg}$ of GG enhance the \%ILS of tumor bearing mice by $40.9 \%$, $68.44 \%$ respectively. This shows that \%ILS of tumor bearing mice was enhanced by increasing the dose. The combination treated groups with half the dose of cisplatin (ie, $1.75 \mathrm{mg} / \mathrm{kg}$ ) with GG $500 \mathrm{mg} / \mathrm{kg}$ also enhance the \%ILS by $93.67 \%$

Prolongation of life span is a reliable criteria for judging the anticancer efficacy of any compound. An enhancement of life span by $25 \%$ or more over that of control was considered as effective antitumor response. In the present study both the doses of GG met this criteria.

Anemia and myelosuppression have been very commonly observed in ascites carcinoma. In EAC control mice elevated WBC count, and reduced hemoglobin and RBC count was observed. Anemia seen in ascites carcinoma is mainly due to iron deficiency, either by hemolytic or myelopathy conditions which lead to reduced RBC number. The major problems of cancer chemotherapy with the conventional drugs are myelosuppression and anemia. The Ethanolic extracts at both the doses tries to normalize the altered hematological parameters by enhancing the hemoglobin and total RBC levels and reducing the $\mathrm{WBC}$ levels in tumor bearing mice. But the effect is more at $500 \mathrm{mg} / \mathrm{kg}$ when compared to $250 \mathrm{mg} / \mathrm{kg}$ of GG. It also restored the serum enzyme levels SGPT, SGOT, ALP, Serum Creatinine, Total protein and Serum Urea to near normal which indicates less toxicity. The Standard drug Cisplatin at a dose $3.5 \mathrm{mg} / \mathrm{kg}$ produces elevated levels of S. Creatinine and urea indicating its nephrotoxic effect. But combination treated groups with half the dose of cisplatin $(1.75 \mathrm{mg} / \mathrm{kg})$ along with 500 $\mathrm{mg} / \mathrm{kg}$ of ethanolic extract reduces the nephrotoxic effect by reducing the $\mathrm{S}$. Creatinine and urea levels and also enhances the MST and \%ILS

Since, the Ethanolic extract of GG leaves showed similar anticancer activity by increasing mean survival time and percentage increase in life span as that of standard the mechanism of action may be because of the potent antioxidant activity of the extracts. However, further studies are required to support the assumption.

\section{CONCLUSION}

The study shows that ethanolic extract of GG has good anti-tumour activity against, EAC cell lines, adding the hematological and biochemical parameters shows beneficial affects which can help in having lesser side effects. These important and significant preliminary finding can be taken as the basis upon which further studies should be carried out to delineate the detailed profile of these anti-cancer actions of Glycyrrhiza glabra

\section{ACKNOWLEDGEMENTS}

The study was supported by JSS University from the Research Promotion Fund of the University.

Funding: No funding sources

Conflict of interest: None declared

Ethical approval: The study was approved by the Institutional Ethics

JSSMC/PR/IAEC/7/4419/2013-14

\section{REFERENCES}

1. Gennari C, Castoldi D, Sharon O. Natural products with taxol-like antitumor activity: synthetic approaches to eleutherobin and dictyostatin. Pure and Appl Chem. 2007;79(2):173-80.

2. Kinghorn AD, Chin YW, Swanson SM. Discovery of natural product anticancer agents from biodiverse organisms. Current Opinion in Drug Discovery and Development. 2009;12(2):189-96.

3. Masoud SG, Mohammadi A, Safiallahy S, Faradmal J, Azizi M, Ahmadvand Z. The effect of aqueous extract of glycyrrhiza glabra on herpes simplex virus 1. Jundishapur J Microbiol. 2014;7(7):e11616.

4. Nassiri-Asl M, Hosseinzadeh H. Review of pharmacological effects of Glycyrrhiza sp. and its bioactive compounds. Phytother Res. 2008;22:70924.

5. Wagner $\mathrm{H}$, Bladt. Plant drug analysis. $2^{\text {nd }}$ eds. Newyork. Springer Verlag Berlin Heidelberg; 2001.

6. Swathy B, Lakshmi SM, Kumar AS. Review on herbal drugs for analgesic and anti-inflammatory activities. IJBPR. 2010;1(1):7-12.

7. Ammosov S, Litvinenko VI. Triterpenoids of plants of Glycyrrhiza L. and Meristotropis Fisch. Et Mey Genuses. Pharm Chem J. 2003;37:83-94.

8. OECD, Guidelines for testing of chemicals, Acute oral toxicity, Environmental Health and Safety Monograph Series on Testing and Adjustment No; 2001:425.

9. Jagetia GC, Venkatesh VAK. Enhancement of radiation effect by Aphanamixis polystachya in mice transplanted with Ehrlich ascites carcinoma. Biol pharma Bull. 2005;28(1):69-77.

10. Haldar PK, Bhattacharya S, Kar B, Bala A, Mazumder UK. Chemoprventive role of Indigofera as palathoides in 20- methylcholanthrene induced carcinogenesis in mouse. Toxicol and Enviro Chem 2010;92:1749-63.

11. Pramod SG, Jayanthi MK, Mryuthunjaya K, Manjula $\mathrm{SN}$ et al. In-vivo anticancer activity of aqueous extract of holoptelea integrifolia leaves against 
Ehrlich ascites carcinoma in swiss albino mice.International Journal of Pharma and Bio Sciences. 2015;6(2):217-25
Cite this article as: Jayanthi MK, Subba Rao MSVT, Reddy DK, Mryuthunjaya K, Manjula SN. Evaluation of anti-tumor activity of ethanolic extract of Glycyrrhiza glabra against ehrlich ascites carcinoma in swiss albino mice. Int J Basic Clin Pharmacol 2016;5:2153-8. 